\title{
Passive Movements of the Head Do Not Abolish Anticipatory Firing Properties of Head Direction Cells
}

\author{
Joshua P. Bassett, ${ }^{1}$ Michaël B. Zugaro, ${ }^{2}$ Gary M. Muir, ${ }^{1}$ Edward J. Golob, ${ }^{1}$ Robert U. Muller, ${ }^{3,4}$ and \\ Jeffrey S. Taube ${ }^{1}$ \\ ${ }^{1}$ Department of Psychological and Brain Sciences, Center for Cognitive Neuroscience, Dartmouth College, Hanover, New Hampshire; \\ ${ }^{2}$ Centre National de la Recherche Scientifique, College de France, Laboratoire de Physiologie de la Perception et de l'Action, Paris, \\ France; ${ }^{3}$ Medical Research Council Centre for Synaptic Plasticity, University of Bristol, Bristol, United Kingdom; and ${ }^{4}$ Department of \\ Physiology, State University of New York, Downstate Medical Center, Brooklyn, New York
}

Submitted 19 May 2004; accepted in final form 27 September 2004

Bassett, Joshua P., Michaël B. Zugaro, Gary M. Muir, Edward J. Golob, Robert U. Muller, and Jeffrey S. Taube. Passive movements of the head do not abolish anticipatory firing properties of head direction cells. J Neurophysiol 93: 1304-1316, 2005. First published October 6, 2004; doi:10.1152/jn.00490.2004. Neurons in the anterior dorsal thalamic nucleus (ADN) of the rat selectively discharge in relation to the animal's head direction (HD) in the horizontal plane. Temporal analyses of cell firing properties reveal that their discharge is optimally correlated with the animal's future directional heading by $\sim 24 \mathrm{~ms}$. Among the hypotheses proposed to explain this property is that ADN HD cells are informed of future head movement via motor efference copy signals. One prediction of this hypothesis is that when the rat's head is moved passively, the anticipatory time interval (ATI) will be attenuated because the motor efference signal reflects only the active contribution to the movement. The present study tested this hypothesis by loosely restraining the animal and passively rotating it through the cell's preferred direction. Contrary to our prediction, we found that ATI values did not decrease during passive movement but in fact increased significantly. HD cells in the postsubiculum did not show the same effect, suggesting independence between the two sites with respect to anticipatory firing. We conclude that it is unlikely that a motor efference copy signal alone is responsible for generating anticipatory firing in ADN HD cells.

\section{IN T R O D U C T I O N}

Head direction (HD) cells are neurons that selectively discharge in relation to an animal's head direction in the horizontal plane. A given HD cell fires only when the animal is facing a direction that falls within a limited angular range, decreasing in rate as the head moves in either direction from a maximum in the center of its range, called the preferred firing direction. HD cells are not sensitive to the position of the head relative to the body but rather to the direction of the head with respect to the surrounding environment, and they fire independently of the animal's location within the environment. They are believed to represent the directional heading information necessary for navigational behaviors as part of a larger spatial cognition circuit involving many structures within the limbic system.

HD cells have been studied primarily in rats and have been found in several regions including the postsubiculum (PoS) (Taube et al. 1990a), anterior dorsal thalamic nucleus (ADN)

Address for reprint requests and other correspondence: J. S. Taube, Dept. of Psychological and Brain Sciences, Dartmouth College, 6207 Moore Hall, Hanover, NH 03755 (E-mail: jeffrey.taube@dartmouth.edu).
(Taube 1995), lateral mammillary nuclei (LMN) (Blair et al. 1998; Stackman and Taube 1998), retrosplenial cortex (Chen et al. 1994; Cho and Sharp 2001), parts of prestriate cortex (Chen et al. 1994), and dorsal striatum (Wiener 1993). HD cells within the ADN, retrosplenial cortex, and LMN have been observed to fire in a manner that encodes the rat's future directional heading by an average of $24 \mathrm{~ms}$ in ADN (Blair and Sharp 1995; Taube and Muller 1998), $25 \mathrm{~ms}$ in the retrosplenial cortex (Cho and Sharp 2001), and $67 \mathrm{~ms}$ in LMN (Stackman and Taube 1998; cf. Blair et al. 1998), respectively. In contrast, HD cell discharge in the PoS corresponds most closely with directional heading in the present or recent past ( 0 ms) (Blair and Sharp 1995; Taube and Muller 1998). The amount of time that peak firing precedes head direction is referred to as the anticipatory time interval (ATI). The observation that HD cells in some brain areas anticipate future head direction is further evidence that HD cell activity is not simply a sensory response to external cues but rather an abstract representation of spatial relationships within the local environment.

One hypothesis proposed to account for this phenomenon is that anticipatory HD cell signals combine sensory input from the recent past with motor information to predict future sensory input, thereby updating the directional representation (Taube and Muller 1998). According to this view, the anticipatory properties of ADN HD cells may arise from motor commands projected to the ADN (or elsewhere in the HD circuit) as motor efference copy signals. There is ample precedent in the study of sensorimotor integration for such a mechanism (von Holst and Mittelstaedt 1950). As a convergence point for cortical and subcortical projections from structures possibly involved in generating the $\mathrm{HD}$ signal, the ADN is anatomically wellsituated to receive and integrate information about environmental cues and self-motion. Vestibular and possibly optokinetic cues contribute to HD signal updating based on selfmotion monitoring, probably via routes from the vestibular nuclei $\rightarrow$ nucleus prepositus $\rightarrow$ dorsal tegmental nucleus $\rightarrow$ lateral mammillary nuclei $\rightarrow$ ADN (Bassett and Taube 2001a; Blair and Sharp 1996; Lannou et al. 1984; Stackman and Taube 1997; Taube 1998). Routes by which motor information could reach ADN HD cells are less clear but could involve projec-

The costs of publication of this article were defrayed in part by the payment of page charges. The article must therefore be hereby marked "advertisement" in accordance with 18 U.S.C. Section 1734 solely to indicate this fact. 
tions from the medial frontal cortex, a motor or supplementary motor area containing putative frontal eye fields and vibrissae and forelimb representations (Neafsey et al. 1986). This area projects both to the retrospenial cortex (Vogt and Miller 1983) and directly to ADN (Guandalini 2001). Subcortical sources of motor information for ADN HD cells are currently unknown. In contrast to the ADN, HD cells in the PoS are not, on average, anticipatory, but instead correspond to current head direction or a small delay [ $-7 \mathrm{~ms}$ (Taube and Muller 1998); 2 ms (Blair and Sharp 1995)]. While it is clear that HD cell firing in $\mathrm{PoS}$ is dependent on an intact ADN (Goodridge and Taube 1997), how the temporal firing properties of the two areas are related is unknown.

Previous efforts to subject rats to passive movement while recording from HD cells have often involved substantial restraint of the animals, such as wrapping them in a cloth so that they cannot move either head or limbs (Golob et al. 1998; Knierim et al. 1995; Taube 1995). Under such conditions, most (but not all) HD cells undergo considerable reductions of firing rate or cease firing altogether. Here, we imposed passive movement on rats while restraining them as little as possible. There were two passive movement conditions: hand-held and cart. In the hand-held passive condition, rats were lightly restrained by an experimenter and then rotated back and forth in the horizontal plane through $\sim 180^{\circ}$ about the preferred firing direction. They were thus limited in their orienting movements relative to the environment but could still respond reflexively with head and postural movements. In the cart condition, rats were moved around the recording arena in a cart with clear Plexiglas walls and thus were able to move freely inside, while their vestibular and visual experiences were dominated by the imposed movement. In both cases, the animals had some freedom to move on their own onto which we imposed passive movement. The cart experiment was included as a control against the predictable movement pattern of the hand-held condition because the experimenter typically rotated the animal back and forth in a semi-regular manner. In addition, the cart experiment provided a different degree of movement restriction against which to compare the results of the passive hand-held condition. We recorded both ADN and PoS cells under the same experimental conditions to compare them and specifically to determine if changes in one corresponded with changes in the other.

The aim of the present experiments was not to restrict head movement to exclusively passive motion but rather to interfere with the normal flow of motor information and determine whether the anticipatory properties of ADN HD cell activity remained present. All movements were some combination of self-initiated and passive motion. The hand-held condition minimized (but did not eliminate) active movements, whereas the cart condition added passive movement to an unrestricted range of active movements. If anticipatory HD cell firing reflects the convergence of motor and sensory information, then one would expect an imposed mismatch between the two to alter the anticipatory property of HD cell activity. In the present experiments, rats experienced vestibular and visual cues that were imposed on it and that could not be associated with a motor efference copy signal corresponding to their head-in-space movements. We predicted that the ATI would be reduced or abolished in animals that did not actively control the movement of their head through a cell's preferred firing direction.

\section{METHODS}

\section{Subjects and training}

Subjects were 17 female Long-Evans rats, weighing 250-300 g. Rats were maintained on a food-restricted diet (15-20 g/day) and housed separately in suspended wire mesh cages. Tap water was available ad libitum except during procedures requiring water reward (see following text). All training and unit screening took place while rats foraged for food pellets in a gray cylindrical enclosure $(76 \mathrm{~cm}$ diam, $51 \mathrm{~cm}$ high) with replaceable gray photographic backdrop paper covering the floor. A black curtain extending from the floor to the ceiling enclosed the training/recording environment, and lighting was provided by uniformly arranged DC lights overhead. A color video camera (model XC-711; Sony, Tokyo, Japan) was centered above the cylinder $3 \mathrm{~m}$ from the floor surface. The only intentionally introduced asymmetry in the environment was a white cue card that occupied $100^{\circ}$ of arc along the wall of the cylinder. Rats were habituated to the cylinder and trained to forage for small pellets $(45 \mathrm{mg}$, Bio-Serv, Frenchtown, NJ) tossed randomly into the cylinder. By the completion of training, rats engaged in nearly continuous food pellet foraging, moving over the entire floor surface of the cylinder. All procedures involving the rats were performed in compliance with institutional standards set forth by the National Institutes of Health Guide for the Care and Use of Laboratory Animals and the Society for Neuroscience.

\section{Surgery}

Electrode construction and implantation has been described in detail previously (Taube et al. 1990a). Each electrode array consisted of ten 25- $\mu$ m-diam nichrome wires (California Fine Wire, Grover City, CA) insulated except at the tips. The wires were passed through a 26-gauge, $\sim 2$-cm-long stainless steel cannula, and each wire connected to a modified 10-pin Augat connector. The electrode array could be advanced in the dorsoventral plane through the use of three screws attached to an acrylic base on the electrode (Kubie 1984). After $\geq 1$ wk of training ( 1 trial/day), each rat was anesthetized with a ketamine-xylazine mixture $(2 \mathrm{ml} / \mathrm{kg} \mathrm{im})$ and stereotaxically implanted with an electrode array directed at the ADN $(n=11)$ or PoS $(n=6)$. Coordinates (in $\mathrm{mm})$ were as follows, from bregma: ADN: $\mathrm{A} / \mathrm{P}-1.4 ; \mathrm{M} / \mathrm{L} \pm 1.3 ; \mathrm{D} / \mathrm{V}-4.0$ from cortical surface. PoS: A/P -6.8; $\mathrm{M} / \mathrm{L} \pm 2.7 ; \mathrm{D} / \mathrm{V}-2.0$ from cortical surface (Paxinos and Watson 1998). Two stainless steel screws each were placed in the skull posterior to lambda and anterior to bregma, and dental cement anchored the electrode in place. Rats were allowed $\geq 1$ wk of postoperative recovery before single-unit screening was started.

\section{Single-unit recording}

The activity on each electrode wire was assessed during daily screening sessions while the rat foraged for food pellets in the cylinder. The electrode wires were advanced over several weeks while screening for single-unit waveforms that were sufficiently isolated from background electrical noise. Rats were transported into the screening/recording area in a covered cardboard enclosure. Each rat was momentarily restrained while a recording cable was attached to the implanted electrode and then released into the cylinder from an entry point that was varied in a pseudo-random manner.

Electrical signals from the electrode wires were passed through a field-effect transistor in a source-follower configuration through an overhead commutator (Biela Development), amplified (Grass Instruments, P5 Series), band-pass filtered (300-10,000 Hz, $3 \mathrm{~dB} /$ octave: Peavey Electronics, Model No. PME8), and then passed through a 
series of window discriminators (BAK Electronics, Model Mo. DDIS1). The resultant signal was then displayed on an oscilloscope (Tektronix, Model No. 2214). Electrode activity was monitored while observing the rat's behavior on a video monitor. Two light-emitting diodes (LEDs) attached to the recording cable were visible to the camera mounted overhead. The $x, y$ coordinates of a red LED positioned over the rat's snout and a green LED positioned over its back were monitored at $60 \mathrm{~Hz}$, the relative position of the two lights indicating the directional heading of the rat and its position in the cylinder. If no HD cell activity was found, the electrode was advanced further into the brain, and the screening process was repeated at least daily and with $\geq 2 \mathrm{~h}$ between screening sessions. When the waveform of a cell could be sufficiently isolated from background noise, the LED coordinates and neuronal discharges were sampled at $60 \mathrm{~Hz}$ and acquired by a data-acquisition interface board (National Instruments, Model No. DIO-96) in a personal computer (Macintosh Quadra $840 \mathrm{AV}$ ). Data were stored for subsequent off-line analyses using LabView software programs (National Instruments). During recording sessions, white noise was played over a speaker mounted on the ceiling and centered above the cylinder to mask uncontrolled auditory cues.

\section{Data analysis}

Three methods were used to determine the temporal relationship between head direction and cell activity: time-shifted optimization of peak firing rate, time-shifted optimization of information content, and separation angle.

OPTIMIZATION FOR PEAK FIRING RATE. During the recording of HD cell activity, cell firing and head direction are monitored simultaneously; the number of spikes fired within a given directional range is then divided by the amount of time the rat's head spent pointing in that range, yielding the firing rate in each direction. Because the spike train and head direction are monitored independently of each other, each data series can be shifted in time relative to the other. Parameters such as peak firing rate and information content (discussed in the following text) are usually reported when samples of head direction and spike activity are aligned in time. These parameters can be optimized, however, by shifting the samples forward or backward in time. For example, the calculated peak firing rate will be highest when time samples containing the greatest cell activity are distributed through the smallest directional range. In the case of ADN and LMN HD cells, the peak firing rate is optimized when head direction is shifted forward in time relative to the spike train. The number of samples shifted to reach this optimized value is defined as the ATI. Positive ATI values indicate anticipatory firing, whereas negative values indicate firing that lags head direction.

The spike time series was shifted forward or backward in time in $1 / 60$ th-s intervals $(16.6 \mathrm{~ms})$ relative to the head direction time series. The shift that produced the highest peak firing was defined as the amount by which cell firing preceded or followed the head's passing through the preferred firing direction.

OPTIMIZATION FOR INFORMATION CONTENT. Information content estimates the amount that a cell's firing reduces the uncertainty of the rat's head direction. This measure has been discussed in detail elsewhere (Skaggs et al. 1993), but briefly, if a cell fired exclusively and reliably in only 1 of the $60\left(6^{\circ}\right)$ angular bins, then head direction would be known to 1 part in 60 or one part in $\sim 2^{5.9}$. Thus the information per spike would be 5.9 bits. Because HD cells have a firing range $>6^{\circ}$ and often have a small amount of background activity outside the cell's directional firing range, information content for ADN HD cells is not typically $>2.8$ bits (Taube and Muller 1998). Information content is given by

$$
\mathrm{IC}=\sum p_{\mathrm{i}}\left(\lambda_{\mathrm{i}} / \lambda\right) \log _{2}\left(\lambda_{\mathrm{i}} / \lambda\right)
$$

where $p_{i}=$ time spent with the head pointing in the $i$ th bin divided by the total time (probability that the head pointed in the $i$ th bin); $\lambda_{i}=$ the mean firing rate of the cell in the $i$ th bin; and $\lambda=$ the overall firing rate of the cell for the entire recording session.

SEPARATION ANGLE. The preferred firing direction for each function was determined by calculating the mean firing direction based on weighting the firing rate for each directional bin within the directional firing range. The directional firing range was defined as the range of head directions over which elevated discharge occurred (see Taube et al. 1990a). The angular difference between the preferred firing directions of the two functions was labeled $\partial$ using the nomenclature of Blair and Sharp (1995). A cell whose firing anticipates or trails head direction will reach its peak firing rate at different directions; the greater the lead or lag, the greater the expected angular difference between peak firing rates for clockwise $(\mathrm{CW})$ and counterclockwise (CCW) turns. Because the anticipatory firing of ADN HD cells is independent of angular head velocities (Taube and Muller 1998), the angular difference between $\mathrm{CW}$ and $\mathrm{CCW}$ tuning curves ( $\partial$ ) tends toward zero at very low angular head velocities. Because of this tendency, analyses using decomposed curves have typically excluded samples where instantaneous angular velocity is $<90 \%$ s. Probability distributions of angular head velocity across a session reveal a strong bias toward the lowest angular head velocities. Thus to increase the total number of samples included when plotting firing rate by head direction functions, we elected to use those samples containing an angular head velocity of $>45 \%$. However, selecting different cut-off values for angular head velocity, either higher or lower than $45 \%$ (e.g., 0 or $90^{\circ}$ ), did not significantly change the overall effects reported in the following text. Multiple curves were constructed using data series that were time-shifted forward and backward by six $1 / 60$ th-s $(16.6 \mathrm{~ms})$ intervals. We constructed a plot of $\partial$ versus time shift and defined the $x$ intercept of the best-fit line as the ATI for the cell. This measure is referred to as "separation angle" and is identical to the measure described by Blair and Sharp (1995) with the exception that we did not approximate the original firing rate versus head direction functions with Gaussian distributions. ATI values are calculated for all measures as the number of video samples shifted and then reported in milliseconds (i.e., the number of samples shifted multiplied by 16.6). The dispersion of ATI values is reported with the SE. Statistical comparisons between groups were conducted using a one-way ANOVA with Tukey honestly significant difference tests (HSD) used for post hoc comparisons when the ANOVA was significant $(P<0.05)$.

To evaluate the interdependence of HD cell firing properties under different experimental conditions, we calculated the area under the curve for the firing rate by head direction functions. The area under the curve corresponds to the sum of the firing rates for each directional bin within the directional firing range. The directional firing range was defined as the set of contiguous directional bins in which neuronal firing rate exceeded the mean background firing rate and also contained the directional bin with the highest firing rate for the session.

We evaluated variability in the preferred firing direction between individual passes through the directional firing range by plotting head direction and firing rate as a function of time. Mean head direction and firing rate was calculated over 10-sample temporal bins ( 1 sample $=$ $1 / 60$ th $\mathrm{s} ; 1$ temporal bin $=1 / 6$ th $\mathrm{s})$. For each episode in which the head passed through a directional range of $24^{\circ}$ (four $6^{\circ}$ directional bins) on either side of the mean preferred firing direction for the overall session, we sampled the exact head direction for the temporal bin containing the highest firing rate for that episode. We refer to this head direction for individual passes through the preferred firing direction as the "instantaneous preferred firing direction," and the firing rate at this direction as the "instantaneous peak firing rate." Instantaneous preferred firing directions were sampled over the full recording session for each cell. Because differences in ATI would affect the spread between $\mathrm{CW}$ and $\mathrm{CCW}$ instantaneous preferred directions (see explanation for separation angle in the preceding text), 
the SD was calculated separately for $\mathrm{CW}$ and $\mathrm{CCW}$ turns. SDs were then compared between active and passive conditions.

We show in RESULTS that there was variability in the preferred firing direction in the passive conditions. This variability could affect the ATI. We therefore modeled the effects of passive movement on the directional tuning function by adding directional noise according to a pseudo-Gaussian probability function and determined whether this effect altered the ATI. As described in the preceding text, each recorded spike is assigned to a $6^{\circ}$ directional bin according to the position of the LEDs on the rat's head during the time interval in which the spike was sampled. When noise was added, each such assignment was made with some probability that the directional sample for that spike would be altered by addition or subtraction of a variable amount, thereby potentially changing the bin assignment. For example, if $6^{\circ}$ of noise was added, each spike sample during that session would have a 0.4 probability of being assigned to its true directional bin, a 0.4 probability of having $3^{\circ}$ added or subtracted before its bin assignment, and a 0.2 probability of being shifted $6^{\circ}$ in either direction. If $12^{\circ}$ of noise was added, there would again be 0.4 probability of no change, 0.4 probability of a shift by $6^{\circ}$ in either direction, and 0.2 probability of a $12^{\circ}$ shift in either direction. This method of adding directional noise was intended to model the effects of increased uncertainty of head direction at a given moment that would occur due to decreased information to the HD cell system during passive movements.

All mean values are reported \pm SE.

\section{Experimental conditions}

Rats were recorded under three conditions: active movements, passive movements while loosely restrained, and passive movements in a cart.

ACTIVE. Active sessions consisted of 8 min of sampling during free foraging behavior under conditions identical to screening sessions as described in the preceding text.

PASSIVE. Following an active session, the experimenter held the rat while supporting its feet, in a manner that restricted movement as little as possible while keeping the rat in place and under control of the experimenter. Unlike hand-held passive motion conditions in previous studies, rats were not bound or restrained in a towel. Rats had full freedom of movement of the head and neck and were able to make limited limb movements and postural adjustments. Rats were rotated at $\sim 180-270^{\circ} / \mathrm{s}$, through a range of $\sim 180^{\circ}$, resulting in peak head velocities (imposed plus self-initiated head movement) of $837.3 \%$ and mean head velocities of $96.5 \%$ s on average (see Fig. 6). Rotations of the rat were centered around the preferred firing direction of the recorded HD cell as determined from the standard session. Each hand-held session consisted of 2 min of sampling, representing onequarter of the normal sampling time. During the last $20 \mathrm{~s}$ of this recording, the rat was rotated through the entire $360^{\circ}$ to sample all directions. Because of the difficulty of controlling a loosely restrained animal, passive sessions generally consisted of two combined 1-min sessions. After passive sessions, the rats were again recorded for 8 min during free foraging so that firing parameters from before and after the passive session could be compared. Figure 1 shows the characteristic movement patterns of each condition.

CART. To achieve the desired uncoupling of sensory and motor feedback in a manner that did not require restraining or touching the rat, we used an additional condition. The rat was placed on a cart with a $22 \times 22 \mathrm{~cm}$ square wood floor on which rested a clear Plexiglas enclosure, $20 \times 20 \times 14 \mathrm{~cm}$ high. The platform and enclosure rested on four swiveling wheels that held the platform $4 \mathrm{~cm}$ off the ground. The cart was then rotated at a rate, and over a range, similar to the passive sessions in rate and range, but the rat was free to move within the clear enclosure. In this way, the rat's freedom to move was completely unrestrained by the experimenter, but its vestibular and visual feedback were affected by the imposed movement. Thus in the hand-held condition, motor commands initiated by the rat were entirely disconnected from passes through the preferred firing direction. By contrast, in the cart condition, the rat's self-initiated movements could lead to turns through the preferred firing direction, albeit with passive motion added to its active movements. Each cart session consisted of $4 \mathrm{~min}$ of sampling. Cart sessions were also bracketed by freely moving standard sessions in the cylinder.

At the completion of the experiments, animals were killed, their brains perfused with $10 \%$ formalin, soaked in $20 \%$ sucrose, frozen, and then sectioned $(40 \mu \mathrm{m})$ on a cryostat (see Taube 1995; for details on histology). Sections were examined under a microscope and electrode tracks were reconstructed. All HD cells were found to be in the intended target sites of ADN or PoS.

\section{RES ULTS}

\section{ADN HD cells}

HAND-HELD PASSIVE CONDITION. We recorded 21 HD cells from the ADN in 11 rats. Results for all conditions are summarized in Table 1. For each measure of ATI, we performed a one-way ANOVA for repeated measures (correlated samples), comparing passive sessions to the preceding and following active sessions. By all measures, ATI values were reliably higher during the hand-held passive session than during the preceding or subsequent active session (peak firing rate $F(2,21)=8.41 ; P<0.001, \mathrm{HSD}_{0.05}=1.42$; information content: $F(2,21)=28.16, P<0.0001, \mathrm{HSD}_{0.01}=1.20$; separation angle $F(2,21)=24.21, P<0.0001, \mathrm{HSD}_{0.01}=$ 1.27). Post hoc comparisons showed no difference between the two active sessions. Thus contrary to our prediction, anticipatory firing was not abolished, but instead showed a significant increase during the hand-held passive condition.

Not every cell in every recording session conformed to this pattern. When the 21 sessions were compared based on optimized peak firing rate, 14 sessions $(66.7 \%)$ showed an increase in ATI during the passive condition relative to the first active condition, 6 sessions $(28.6 \%)$ showed a decrease, and 1 session $(4.8 \%)$ showed no change. The outcome was less varied when data were time-shifted to optimize information content (increase: $95.2 \%$, decrease: $0 \%$, no change: $4.8 \%$ ) or minimize separation angle (increase: $80.9 \%$, decrease: $19.1 \%$, no change: $0 \%$ ). Figure 2 shows a representative tuning function of an ADN HD cell that exhibited an increased ATI during handheld passive rotations.

We also compared other parameters of HD firing across conditions to determine whether these other parameters changed and were related to the changes observed in the ATI. There was a significant effect of condition on both the observed peak firing rate and the directional firing range. Mean observed peak firing rates were lower by $\sim 23 \%$ during passive rotation $[F(2,20)=8.81, P<0.001]$, decreasing from $61.9 \pm 8.9$ spikes/s in the first active session to $47.1 \pm 5.6$ spikes/s during the passive condition, and returning to $60.8 \pm 8.9$ spikes/s in the second active session. Mean directional firing range increased significantly from $97.1 \pm 3.2$ to $113.5 \pm 5.1^{\circ}$ during the passive session $[F(2,21)=8.95, P<0.001]$.

This result appears to contradict the results of Zugaro et al. (2002), who reported that peak firing rates were not significantly different during active locomotion and fast (at least $\sim 150 \%$ s) passive rotations. However, the lower peak firing 

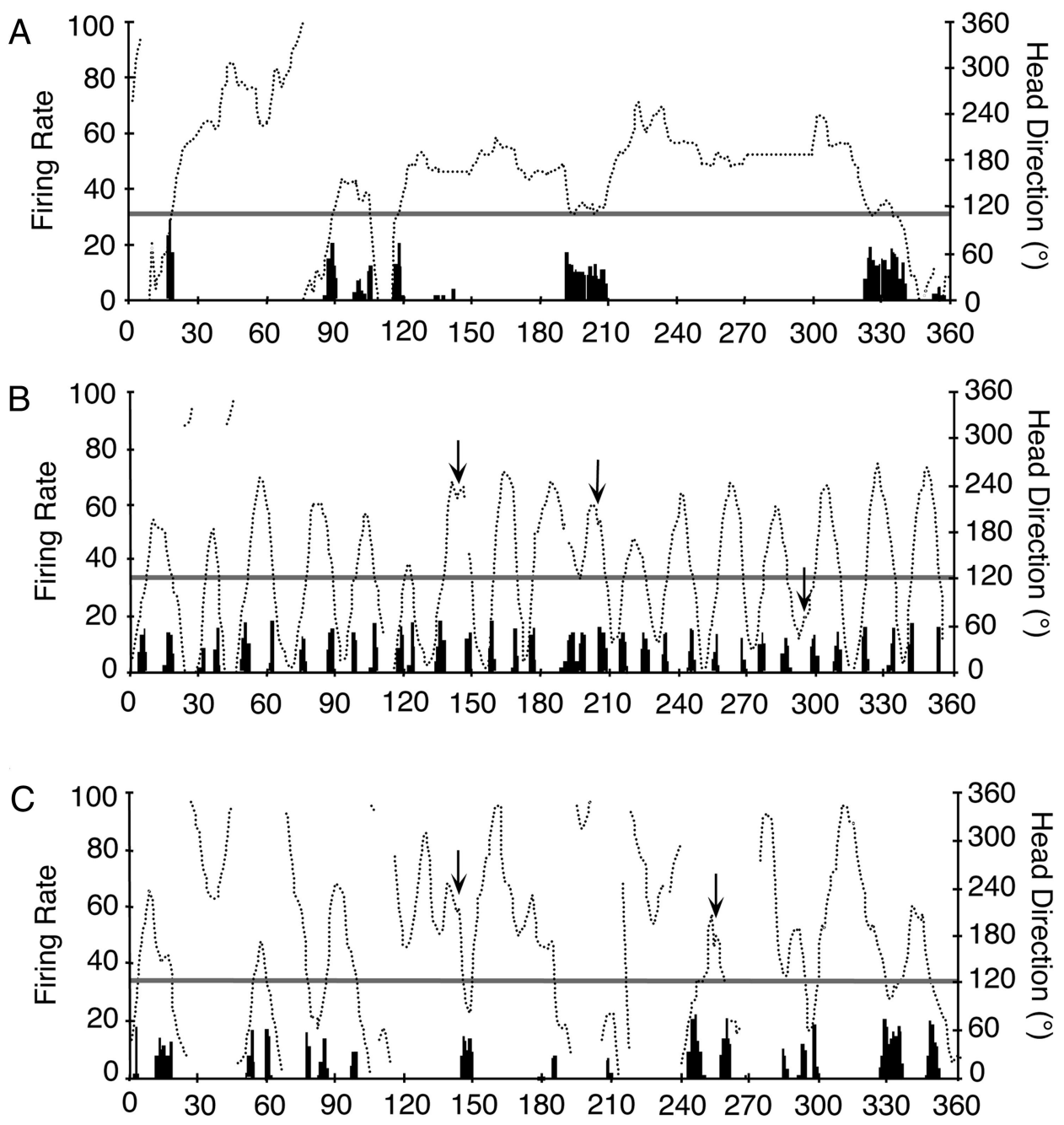

\section{Time $\left(1 / 6^{\text {th }}\right.$ sec bins $)$}

rates observed here during passive rotations could have resulted from some instability in the preferred directions over time, rather than from an actual decrease in peak firing rate. To distinguish between these possibilities, we performed three different analyses: area under the tuning curve, variability of the head direction at times of peak firing, and peak firing rate during individual passes through the directional firing range.
FIG. 1. Head direction and spikes fired as a function of time during active $(A)$, handheld $(B)$, and cart conditions $(C)$. Head direction across time (dotted line) is shown for $1 \mathrm{~min}$ of recording in the same cell from each condition. Each temporal bin on the horizontal axis is $101 / 60$ th-s samples or $1 / 6$ th $\mathrm{s}$. Head direction represents the average $6^{\circ}$ directional bin for these 10 samples. Neuronal spiking (vertical black bars) occurs when the rat's head passes through or near the mean preferred firing direction determined for the entire session (gray horizontal bar). Each bar represents the sum of spikes fired within the temporal bin. Instantaneous preferred firing directions are not identical for each pass (see also Fig. 3). Arrows in $B$ and $C$ indicate examples of head movement initiated by the rat on top of experimenter-imposed movement.
If a cell fired at its maximum rate at slightly different directional headings over time, its HD tuning curve would have a lower peak and a wider directional firing range because the same number of spikes would be averaged over a greater number of directional firing bins. However, if the firing rate for each individual pass of the head through the preferred firing direction was lower, then the total number of spikes would be

TABLE 1. Anticipatory time intervals compared across conditions

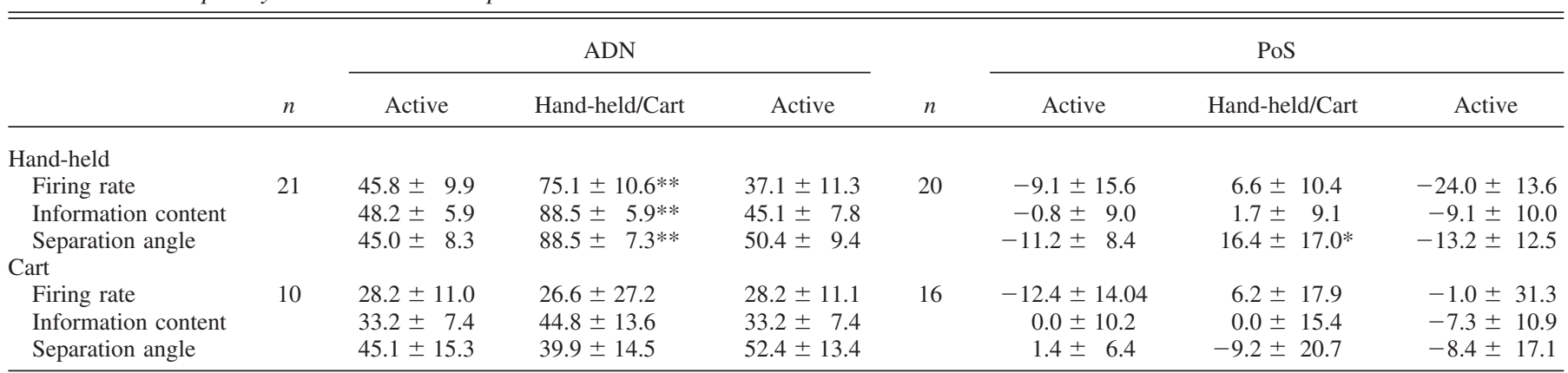

All values are means \pm SE and are reported in milliseconds. ADN, anterior dorsal thalamic nucleus; PoS, postsubiculum. *Significantly different from Active, $P<0.05$; **significantly different from Active, $P<0.01$. 


\section{Combined Function}
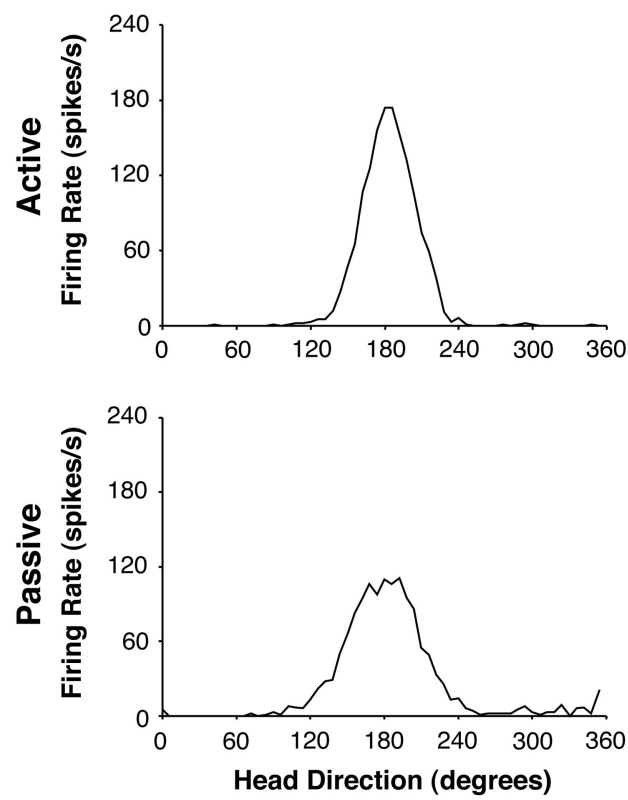

averaged over the same directional range. Given no other changes in HD cell properties besides error in the preferred firing direction, this difference should be reflected in the area under the directional tuning curve between active and passive sessions. If the firing rate was decreased and the directional range remained the same, then the area under the curve would decrease. If the firing rate was the same, but spread out over a wider directional range, then the area under the curve would remain constant.

When we compared the area under the curve for the initial active session and the passive session with a paired $t$-test, we observed no significant difference (mean area for active sessions: 2,948 \pm 475 spike degrees/s; for passive sessions: $2,667 \pm 403$ spike degrees/s; $t=1.79, P>0.05$ ). If the area under the curve is the same, then the decreased firing rate and increased directional range must either be the result of greater variability in the preferred firing direction or a change in the two parameters (peak firing rate and directional range width) in proportion to one another but in opposite directions. The variability in preferred firing direction during a passive session might arise because the available sensory and motor information is insufficient to accurately track current directional heading compared with when the animal is actively moving. If peak firing rate and directional firing range changed in exact proportion but in opposite directions, it would be evidence of a dependence between the two parameters that has not been demonstrated previously.

To evaluate the variability of each cell's preferred firing direction, we determined the preferred firing direction for individual passes of the head through the directional firing range. By plotting firing rate and head direction as a function of time, we sampled the instantaneous preferred firing direction and peak firing rate during each pass of the head through the directional firing range. We first examined whether the peak firing rates for individual passes were similar between active and passive sessions. As in the case of mean peak firing rate determined for a full session, instantaneous peak firing rates
Clockwise vs. rclocwise Functions

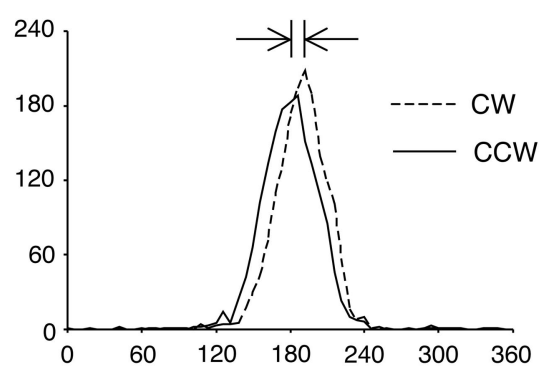

FIG. 2. Examples of changes in the tuning curves from anterior dorsal thalamic nucleus $(A D N)$ head direction (HD) cells between active and hand-held passive conditions. Firing rate as a function of head direction was plotted for a representative cell during the first active session (top) and the hand-held passive session (bottom). Left: head turns in both directions; right: data from the same sessions decomposed into clockwise (CW) and counter clockwise (CCW) functions. A lower peak firing rate and broader directional firing range is evident in both cases. CW functions that occur to the right of $\mathrm{CCW}$ functions indicate anticipatory firing. Right: an increased ATI during the passive session is inferable from the greater separation angle between $\mathrm{CW}$ and $\mathrm{CCW}$ functions (represented by the space between the two arrows). ATI values, as determined by separation angle, are 58.3 and $109.6 \mathrm{~ms}$ for the active and passive sessions, respectively. were significantly higher during active than passive conditions mean instantaneous peak firing rate for active sessions: $74.7 \pm$ spikes/s; passive sessions: $57.1 \pm 6.2$ spikes/s; $t=4.25$ $>0.0005$ ). This result is consistent with previous studies in Thich restaint reduced peak firing rates (Golob et al. 1998; tween active and passive conditions. A paired $t$-test of SDs for the instantaneous preferred firing direction during individua passes through the directional firing range showed a significant (mean SD for active sessions: $13.8 \pm 4.4^{\circ}$; passive sessions: $18.2 \pm$ $\left.10.1^{\circ} ; t=2.02, P<0.01\right)$. Increased variability in the instantaneous preferred firing direction would lead to spikes firing rate and greater directional firing range for the overal session. Figure 3 depicts the variability observed in the precontained greater variability in preferred firing direction Taken together, the area-under-the-curve analysis and the variability in preferred direction for individual passes analysis suggest that the changes we observed in the peak fir sessions for correlations between changes in either peak firing rate or directional firing range and the ATI. The (see Table 2 ). Interestingly, we found a reasonably good correlation between the different measures of ATI where all $r$ values were 

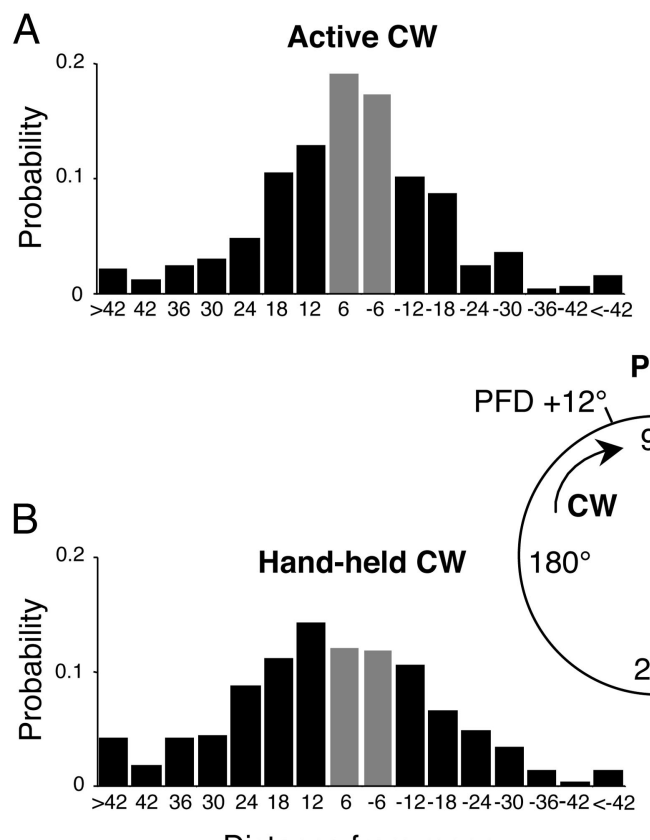

Distance from mean
Active CCW

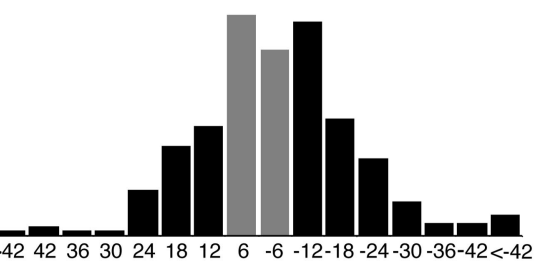

FD

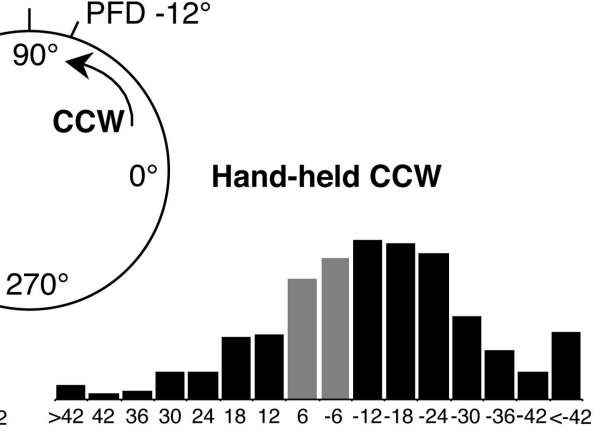

Distance from mean

FIG. 3. Variance in the instantaneous preferred firing direction during active $(A)$ and hand-held $(B)$ conditions. Instantaneous preferred directions were determined for cells during active and hand-held conditions and sorted by turn direction (CW vs. CCW) and deviation from the cell's mean preferred firing direction for both turn directions. For example, if a cell's preferred firing direction was $90^{\circ}$, an instantaneous preferred direction of $83^{\circ}$ would fall into the $-12^{\circ}$ bin (inset). For a cell exhibiting anticipatory firing, instantaneous preferred directions tend to fall to the left of the preferred firing direction during $\mathrm{CW}$ head turns and to the right of the preferred firing direction during CCW head turns. Compared with active foraging conditions, the instantaneous preferred directions during hand-held rotations were shifted away from the preferred firing direction, indicating greater anticipation, and distributions were flatter, indicating greater variance. Bins surrounding $0\left( \pm 6^{\circ}\right)$ are highlighted in gray to illustrate movement of the distributions' centers.

$>0.65$ for the active condition and $>0.50$ for the passive condition. These result differ from those reported previously by Taube and Muller (1998) who reported that all $r$ values $<0.25$. The reason for this difference is unclear.

To further test the independence of ATI changes from changes in peak firing rate and directional firing range, we modeled the effect of imposing passive movements by adding "directional noise" to the spike time series in active sessions. We assumed, in other words, that noise simulates smearing of the preferred direction over time (see Fig. 4A). As expected, directional noise increased the directional range width and lowered peak firing rates. We added noise in increasing $6^{\circ}$ increments to find the amount of noise necessary to model the effect of the passive condition (Fig. 4B). To maximize the correlation between the active and passive conditions for both peak firing rate and directional firing range across the entire cell population, it was necessary to add $\pm 18^{\circ}$ of noise to the active session spike time series, although some cells required more or less than $18^{\circ}$ of noise. The fact that the highest correlation for both directional range width and peak firing rate was achieved with the same level of added noise is further evidence that increased uncertainty about current direction during passive rotations reduces mean peak firing rate independent of the reduction of instantaneous peak firing rate that we also observed (see preceding text).

Adding this level of noise $\left(18^{\circ}\right)$ to active sessions, we then recalculated ATI values and compared them to the ATIs in passive sessions. For all measures of ATI, values for the passive sessions were still significantly higher than active sessions with noise added [peak firing rate: $F(2,21)=8.30$, $P<0.001$; information content: $F(2,21)=32.02, P<0.0001$; separation angle: $F(2,21)=26.65, P<0.0001]$. This result

TABLE 2. Correlation between HD cell firing parameters

\begin{tabular}{|c|c|c|c|c|}
\hline Active & $\begin{array}{c}\text { ATI } \\
\text { (Firing Rate) }\end{array}$ & $\begin{array}{c}\text { ATI } \\
\text { (Information Content) }\end{array}$ & $\begin{array}{c}\text { ATI } \\
\text { (Separation Angle) }\end{array}$ & Peak Firing Rate \\
\hline \multicolumn{5}{|l|}{ Active } \\
\hline ATI (firing rate) & 1.00 & & & \\
\hline ATI (information content) & 0.68 & 1.00 & & \\
\hline ATI (separation angle) & 0.77 & 0.86 & 1.00 & \\
\hline Peak firing rate & 0.07 & -0.01 & 0.07 & 1.00 \\
\hline Directional range width & 0.21 & -0.01 & 0.14 & 0.48 \\
\hline \multicolumn{5}{|l|}{ Passive } \\
\hline ATI (firing rate) & 1.00 & & & \\
\hline ATI (information content) & 0.51 & 1.00 & & \\
\hline ATI (separation angle) & 0.56 & 0.74 & 1.00 & \\
\hline Peak firing rate & -0.30 & -0.24 & -0.06 & 1.00 \\
\hline Directional range width & -0.10 & 0.20 & 0.32 & 0.48 \\
\hline \multicolumn{5}{|l|}{ Change (passive-active) } \\
\hline ATI (firing rate) & 1.00 & & & \\
\hline ATI (information content) & 0.46 & 1.00 & & \\
\hline ATI (separation angle) & 0.57 & 0.75 & 1.00 & \\
\hline Peak firing rate & -0.07 & -0.03 & -0.11 & 1.00 \\
\hline Directional range width & -0.28 & -0.26 & -0.05 & -0.18 \\
\hline
\end{tabular}

HD, had direction; ATI, anticipatory time interval. 

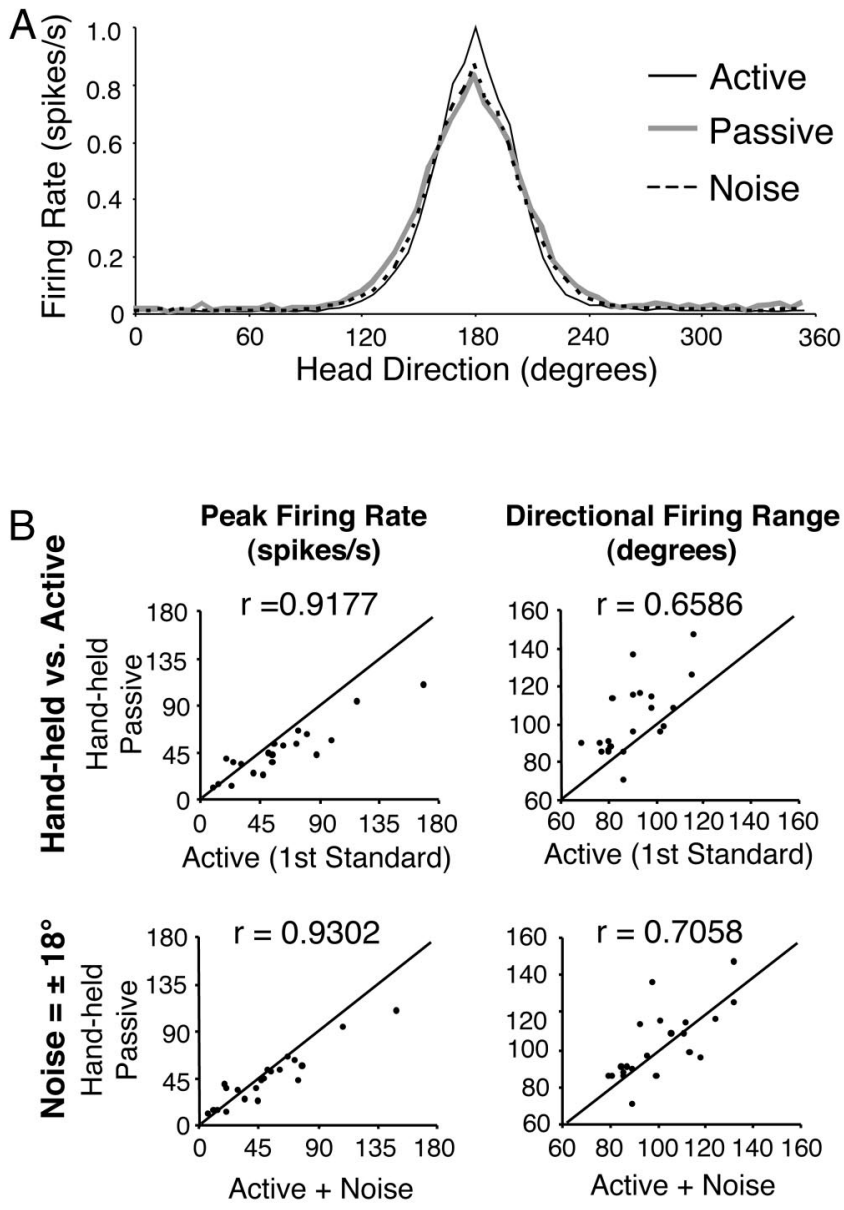

FIG. 4. Effects of directional noise on HD cell firing parameters. A: firing rate $\times \mathrm{HD}$ tuning curves from all $\mathrm{ADN}$ cells in the hand-held passive condition were normalized to the peak firing rate in the first active session of each cell. Each tuning curve was then shifted horizontally along the HD axis such that the cell's peak firing rate was aligned to a $\mathrm{HD}$ of $180^{\circ}$. Mean normalized firing rate as a function of HD for all cells is shown for active and passive sessions and for active sessions with $18^{\circ}$ of directional noise added (see text for details). Peak firing rate is lower and directional firing range is wider for passive and noise trials. $B$ : peak firing rate (left) and directional firing range (right) data are plotted between conditions. In the first row, data for active sessions are plotted against their corresponding data in hand-held passive sessions. In the second row, data for hand-held passive sessions are plotted against active data with $\pm 18^{\circ}$ of directional noise added (see text for details).

indicates that the increased ATI during passive sessions is independent of the increased variability of preferred firing direction and reduced peak firing rate.

CART CONDITION. In the cart condition, the rat was moved passively in a Plexiglas-walled cart that allowed it to move freely relative to the cart floor, but imposed movement on it relative to the spatial cues within the local environment. We tested 10 cells in six rats. Because the rats could move freely in the cart, directional sampling was similar across all directions. To control for differences in sampling time that might affect variability, we compared the 4-min cart sessions with the first 4 min of each active session. Unlike the hand-held passive session, there was no apparent effect of condition on ATI in the cart sessions [peak firing rate: $F(2,10)=0.29, P>0.05$; information content: $F(2,10)=0.81, P>0.05$; separation angle: $F(2,10)=0.48, P>0.05]$. Furthermore, there was no effect of condition on peak firing rate $[F(2,10)=0.78, P>$
$0.05]$ or directional range width $[F(2,10)=1.53, P>0.05]$. Figure 5 shows representative $\mathrm{CW}$ and $\mathrm{CCW}$ tuning functions from a cart session compared with the preceding active control.

ANGULAR HEAD VELOCITY. During passive conditions, the animals' head velocity was the sum of self-determined and imposed velocity. Taube and Muller (1998) showed that ATIs increased in a near-linear manner with angular head velocity for ADN HD cells. Thus conditions or sessions that contained high angular head velocities would be expected to have higher ATI values compared with conditions with low angular head velocities. To determine whether differences in the distribution of different angular head velocities could account for any observed changes in ATI, we examined the distribution of angular head velocities over the course of a recording session for each condition. Figure 6 shows probability distributions for all conditions compared with their respective preceding control sessions. Mean instantaneous angular head velocities were lower during control sessions (active foraging) than during experimental conditions for hand-held and cart trials (active: $57.92 \pm 3.16 \%$, passive: $96.47 \pm 4.68 \%$, cart: $93.30 \pm$ $4.15 \%$ s). Thus this result raises the possibility that velocity is the variable affecting ATI. Three considerations, however, argue against this interpretation. First, there was a poor (and sometimes moderate negative) correlation among cells between mean angular head velocity and ATI $(r=-0.19,-0.42$, and -0.53 for active, passive, and cart sessions, respectively); thus sessions in which angular head velocity was higher did not tend to produce higher ATI values. Second, angular head velocities in the cart condition were higher than in active conditions and similar to hand-held conditions, but did not lead

\section{Cart}
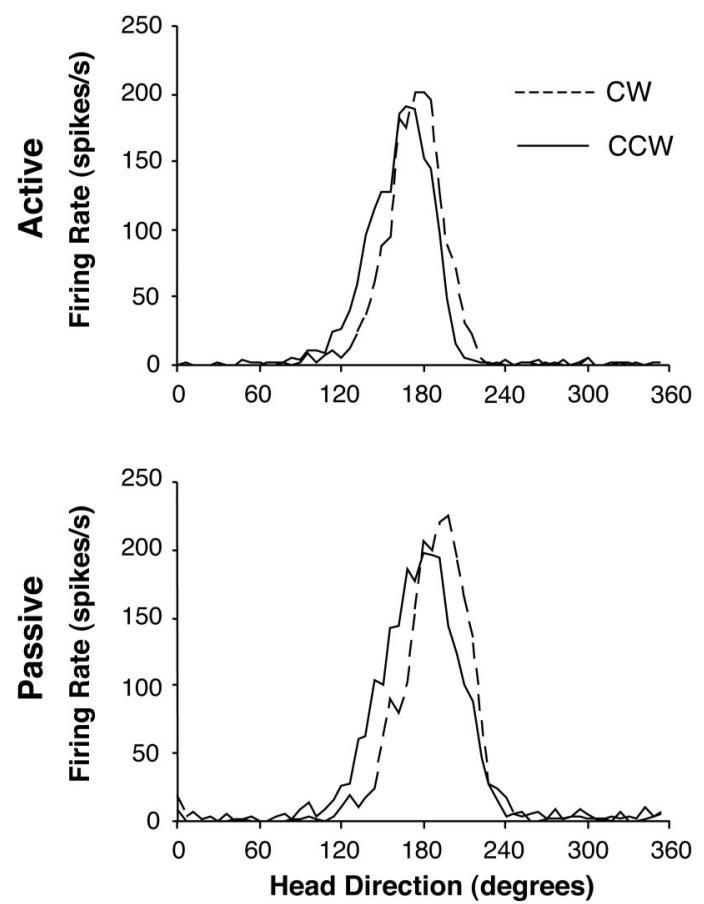

FIG. 5. Examples of changes in the $\mathrm{CW}$ and $\mathrm{CCW}$ tuning curves from $\mathrm{HD}$ cells between active and cart conditions. Firing rate as a function of head direction was plotted for a representative cell during the first active session (top) and the cart condition (bottom). The ATI is not significantly changed, as is evident from the proximity of the $\mathrm{CW}$ and $\mathrm{CCW}$ functions. 

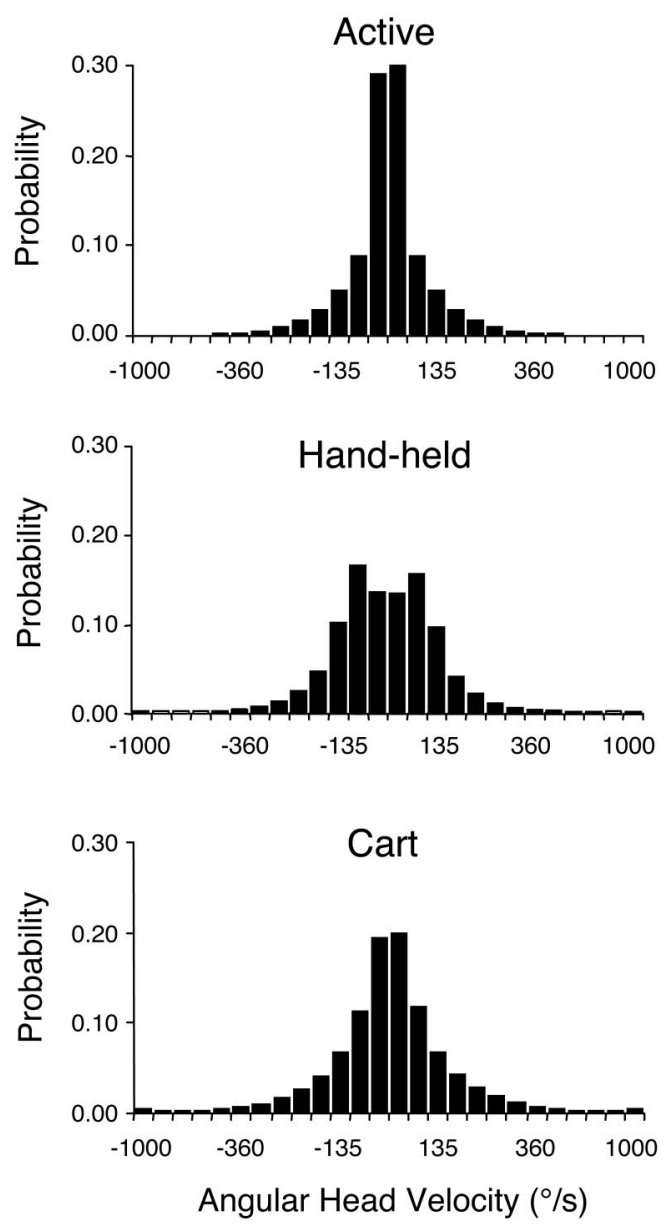

FIG. 6. Changes in angular head velocity (AHV) between conditions. For each probability distribution, instantaneous AHV values for each 1/60th-s sample are grouped in $45 \%$ bins according to probability across the recording session and averaged across all cells within the experimental group. Distributions from active conditions (top) are taken from sessions immediately preceding the hand-held and cart sessions (bottom).

to higher ATIs in the cart conditions. Finally, the separation angle measure excludes samples in which angular head velocity $<45^{\circ} /$ s. Excluding these samples, the mean angular head velocity for each condition was active: $121.83 \pm 2.29^{\circ} / \mathrm{s}$, passive: $123.74 \pm 6.15^{\circ} / \mathrm{s}$, and cart: $143.86 \pm 7.37^{\circ} \%$. Thus for this measure the mean angular head velocity for active and passive conditions were similar, and yet this measure did not lead to lower ATIs compared with the two other measures, i.e., optimization of peak firing rate and information content (see Table 1). Taken together, we consider it unlikely that changes in ATI values between conditions correspond to differences in the angular head-velocity profiles during those sessions. If the higher ATI values in the hand-held condition were indeed the result of higher angular head velocities, this finding would suggest that ATI is more velocity-dependent than previously evident (Taube and Muller 1998).

\section{PoS HD cells}

Because we found that the ATI increased for passive rotations in ADN HD cells, we recorded HD cells in the PoS under the same conditions to determine if similar effects would also be evident in PoS. ATI values in PoS HD cells are typically near zero, and we were thus interested in determining whether ATI values would become more positive during passive sessions as they did for ADN cells. We recorded 20 PoS HD cells in six rats in the hand-held passive condition. There was a trend toward higher ATI values during the hand-held condition, but this trend reached significance for only one measure-separation angle $[F(2,20)=3.79, P<0.032]$; it was not significant for peak firing rate $[F(2,20)=1.92, P<0.160]$ or information content $[F(2,20)=0.90, P<0.415]$. A Tukey post hoc comparison revealed the difference to be between the handheld condition and the second active control trial $\left(\mathrm{HSD}_{0.05}=\right.$ 1.77).

In the Cart condition, we recorded from 16 HD cells from five rats. As in the case for ADN cells, PoS cells showed no significant change across condition for any measure \{peak firing rate: $[F(2,16)=0.21, P>0.05]$; information content: $[F(2,16)=0.17, P>0.05]$; separation angle: $[F(2,16)=0.19$, $P>0.05]\}$. The results from PoS HD cells are summarized in Table 1.

\section{I S C U S S I O N}

We expected that subjecting a rat to passive movement would abolish or reduce the ATI in ADN HD cells. We found no such result, and in at least one type of passive manipulation, we found that there was an increase in the time by which cell firing anticipated HD. Thus our notion of how a motor efference copy signal would drive anticipatory firing is not able to account for this result and requires revision.

\section{Reafference and efference copy}

Since its articulation by Von Holst and Mittelstaedt (1950), the idea of a motor efference copy signal has been associated with comparisons made between afferent input resulting from self-initiated movements (reafference) and the motor signals driving those movements. Such a comparison would reduce ambiguity in situations where changes in afferent stimuli could be the result of either environmental or self-initiated motion. Classic examples involve visual/oculomotor interaction, in which motor information is used to differentiate between eye movements and independent movements of the visual scene in the external environment. In the case of directional orientation, predictable changes in the visual scene and vestibular input should result from angular head movement of a given magnitude. Proprioceptive feedback, related to stretch in the neck, back, and limb muscles, is also available and would modulate ongoing movement planning. Maintaining a correct relationship between movement and reafferent feedback would be fundamental to keeping an accurate sense of orientation. Such a comparison could utilize a model of the expected reafference for error correction, and it was our hypothesis that the anticipatory firing properties of ADN HD cells represent this kind of predictive model. Removing or altering motor information such that it was not consistent with movement of the body/head would therefore impoverish the model and preclude error correction. The finding that anticipatory firing continues under passive conditions indicates that either it is not related to the hypothesized predictive model or that the model is not dependent on motor input.

Our results strengthen previous conclusions (Taube and Muller 1998) that the anticipatory firing characteristics of ADN 
HD cells are independent of other firing parameters, most notably peak firing rate and directional firing range. Although firing rate was reduced under the same conditions that ATI values increased, there was no linear relationship between the two parameters within a condition, nor between the degree of change in firing rate values and in ATI values from the active to the passive condition. Furthermore, we were able to produce distortion of the tuning curves by adding spatial noise in a manner that modeled changes in peak firing rate and directional range width without producing any change in ATI values. This finding may be significant in light of other observed effects of movement on peak firing rate.

Zugaro et al. (2002) reported that during passive rotations in unrestrained rats, peak firing rate decreased significantly at low angular head velocities, but there was no difference between passive and active groups at high angular head velocities. In contrast, earlier investigations of HD cell characteristics observed dramatically decreased firing rates in restrained animals at both low and high angular head velocities (Golob et al. 1998; Knierim et al. 1995; Taube 1995; Taube et al. 1990b). In these studies, animals were immobile, but sometimes struggled against the restraint and consequently generated motor commands. This result suggests that motor efference copy signals modulate the cell's firing rate rather than influence the ATI. During passive movement, angular head velocity may modulate peak firing rate to the degree it does because there is no motor efference copy signal to cancel the vestibular input. Restraint would represent a mixed case: motor signals arising from struggling movements may be sufficient to cancel vestibular modulation of firing rate but not to support motordriven firing rate modulation. According to this view, the HD signal is a summation of sensory and motor signals.

Such a scenario seems plausible in light of research in monkeys that suggests just this type of vestibular-motor integration. Neuronal firing in many vestibular nucleus neurons in monkeys was modulated by angular head velocity only when the head was turned passively and not when the monkey made active head turns (McCrea et al. 1999; Roy and Cullen 2001). One type of neuron [position-vestibular-pause (PVP)] showed suppression of vestibular modulation during gaze redirection (i.e., combined head and eye movement) that ended once the eye-in-space position was stable, showing angular head-velocity modulation only while the head was still turning to bring the head in line with the eyes. Another type of neuron [velocity only (VO)] showed suppression of vestibular modulation through the entire head movement regardless of eye movement. Both types were velocity modulated during passive rotations in the dark. Furthermore, the suppression of modulation only occurred when the monkey turned its head relative to its trunk, thereby activating neck motoneurons and not when the monkey "steered" the apparatus to turn the head and body together (Roy and Cullen 2001). The authors concluded that an efference copy of the neck motor command, rather than higherorder motor commands planning head-in-space position, was responsible for influencing vestibular firing patterns. Similarly, if motor efference copy commands do contribute to the HD cell signal, such commands are likely to originate elsewhere than sites of executive motor planning like the motor cortex. Roy and Cullen's manipulation preserved intention (steering) and movement reafference (vestibular sensation) while removing motor input (head-on-body movements). Our passive manipu- lations preserved movement reafference (vestibular sensation) and motor input (head-on-body movements) while decoupling this information from intention (imposition of passive movement). The results in both cases argue that the kind of mismatches between intended head-in-space movements and sensory feedback that we sought to create would be independent of an efference copy-reafference loop situated between the vestibular nuclei and lower motor centers. During passive conditions, vestibular and visual reafference information would be consistent with one another and correspond normally to the head-on-body component of movements controlled by the spinal motoneurons, even while they deviate from the intended head-in-space movement controlled at the level of motor planning. Indeed, Roy and Cullen (2001) found that the passive and active components of a combined voluntary and imposed movement were differentiated at the neural level in vestibular neurons that fired only in proportion to the passive component. The protocol of Zugaro et al. (2001), in whose study rats were passively rotated while standing at a water spout, would tend to elicit no gaze redirection because the behavioral goal was stationary. Thus the rats would be in a gaze stabilization mode, and in the schema of Cullen and Roy (2004), pure vestibular modulation would be operational in the vestibular nuclei. The hand-held passive condition in our experiments would be comparable to the "reduced vestibular" condition of Roy and Cullen (2004) in which combined passive and active movements in opposite directions resulted in a lower vestibular firing rate in $\mathrm{VO}$ cells. This attenuated firing was putatively suppressed by motor efference copy signals. If the vestibular signals believed to drive HD cell firing interact with motor efference signals in a comparable way, then this situation may explain the different affects on firing rate seen in different passive conditions.

Previous studies that manipulated visual cues or information from motor efference copy/proprioceptive systems have shown that these systems play major roles in controlling a HD cell's preferred firing direction (Stackman et al. 2003; Taube 1995). In contrast, manipulation of vestibular cues, either through transient or permanent lesions of the vestibular labyrinth, has shown that an intact vestibular system is required to generate direction-specific activity (Stackman and Taube 1997; Stackman et al. 2002). While the attenuation of firing that occurred during active head movements in monkeys was obtained from the medial vestibular nuclei, how and where vestibular, motor, visual, and proprioceptive information might be integrated in the HD cell circuit is poorly understood. The ADN receives HD cell information from the lateral mammillary nuclei (LMN) (Blair et al. 1998; Stackman and Taube 1998), which in turn receives its primary inputs from the dorsal tegmental nucleus (DTN) (Allen and Hopkins 1989; Hayakawa and Zho 1989). ADN HD cell activity is dependent on an intact DTN (Bassett and Taube 2001b), and the majority of cells within the DTN encode angular head velocity (Bassett and Taube 2001a; Sharp et al. 2001). The DTN receives one of its major projections from the nucleus prepositus hypoglossi, which is usually thought of as part of the neural integrator for the vestibuloocular-reflex (VOR) and eccentric gaze-holding (Fukushima et al. 1992). While neurons in this structure are typically associated with eye velocity and position correlates, at least some cells were identified in primates (McFarland and Fuchs 1992), rats (Lannou et al. 1984), and gerbils (Kaufman et al. 2000) that 
were sensitive to angular head velocity independent of eye movements. Taken together with the anatomy, these findings suggest that the NPH may be the principal conduit of vestibular-originating head-velocity information to the HD cell system. Its place in the HD cell circuit is intriguing, though, in light of several observations. First is the organization of motor/ vestibular interaction as discussed above with regard to studies in the monkey. At a stage of processing as early as secondary vestibular neurons, cell activity reflects the complex combined head-eye interaction in gaze redirection (Cullen and Roy 2004). Second is the interconnectivity of the NPH not only with the oculomotor complex (particularly the abducens nucleus and medial rectus subdivision of the oculomotor nucleus, subserving horizontal eye movements [McCrea and Baker 1985]) but also with the superior colliculus, a midbrain structure strongly implicated in voluntary gaze direction (Hardy and Corvisier 1996). Finally, there is the observation that rats redirect their gaze primarily through head (rather than eye) movements (Meier and Dieringer 1993), leading to the possibility that HD cell activity incorporates the direction of gaze. Taken together, these observations offer a possible explanation for the shifts we found in ATI during the hand-held passive condition, which we discuss in the next section.

Numerous studies have demonstrated the tendency, in humans and other animals, for the direction of the head to anticipate the trajectory of the body during changes in heading (Grasso et al. 1998). In animals with binocular vision, these head movements are always accompanied by saccades to effect overall gaze (eyes + head) shifts in the direction of anticipated motion. Even in afoveate animals with side-set eyes, however, eye movements are involved in this gaze shift in the sense that the range of motion of reflexive eye movements (nystagmus) is shifted in the direction of movement. Several investigators have thus proposed that aligning the gaze with desired direction of motion-whether the eye-movement portion is voluntary or reflexive-provides the brain with an allocentric reference frame that can be used to guide the whole body along the intended path (Chun and Robinson 1978; Crommelinck et al. 1982). Siegler et al. (1998) have even presented evidence that reflexive gaze shifts are related to the spatial relationships of the remembered features in the surrounding environment. They assessed shifts in the eyes' range of motion during nystagmus (nystagmic "beat-fields") in human subjects exposed to identical vestibular stimulation in the dark, before and after having seen the surrounding room. In each case, they were asked to make judgments about their angular displacement. Beat-field shifts were greater and judgments were more accurate after viewing the surrounding room. Siegler et al. (1998) argued that subjects were orienting to remembered features of the room.

In light of these data, we can imagine how a HD signal could be anticipatory without necessarily relying on a motor-efference copy signal. If vestibular input alone can change the orientation of reflexive eye movements to anticipate the allocentric reference frame, as Siegler et al. argued, then it could change the neural activity underlying the representation of allocentric space. Because this reflexive gaze shift is ultimately a vestibular reflex, the reference frame anticipation need not rely on motor signals any more than anticipation in the VOR does. Instead, anticipation of future head direction could be derived simply from velocity and head-turn direction information, where a current angular head-velocity signal is fed for- ward and integrated into the HD cell circuit to anticipate where the animal's head will be pointing in the immediate future, given the preceding sensory information. A number of predictions arise from this hypothesis. One is that anticipatory firing would remain present even during completely passive rotations because no motor efference signal would be involved. Another is that the ATI would show a linear dependence on angular head velocity. Both of these predictions are consistent with the present results. Another interesting prediction, though more difficult to test, is that the anticipatory mechanism would function poorly at the initiation of a head turn. Little anticipation could occur at the start of a head turn because there would be no previous velocity signal to inform a prediction of future head direction.

The implication of this last prediction is that anticipation would be more robust during movements that contain fewer starts or changes of direction. Accordingly, the relatively long-duration head sweeps (i.e., low frequencies) that are evident in the HD profile of the hand-held condition (Fig. 1) may be the key to explaining the increased ATI values in this condition relative to others and suggests another similarity to the nystagmic beat-field shift phenomenon. First, nystagmic beat-field shifts, like the anticipatory firing in HD cells, are velocity dependent. Second, the beat-field shifts typically conform to a temporal profile in which they first increase in amplitude over time and then gradually subside during extended rotations (Meier and Dieringer 1993). Thus as we would predict for anticipatory HD cell firing, beat field shifts are less robust in the highest-frequency range of movement. The relatively low-frequency movements in the hand-held conditions may allow large shifts of the beat-field to develop, without being so long in duration as to allow the shifts to subside. If anticipatory firing occurs in parallel to nystagmic beat-field shifts, it may follow a similar temporal profile, such that low-frequency/long-duration turns elicit larger ATIs just as they elicit greater beat-field shifts. Although this parallel is speculative, by recording a rat's eye movements along with its directional heading under experimental conditions that lead to a beat-field shift we may be able to test this hypothesis.

Despite this possibility, current evidence does not allow us to confidently attribute any behavioral or functional role to anticipatory firing. Some models of HD cell activity posit anticipatory firing as an emergent property of the network (Goodridge and Touretzky 2000; Hahnloser 2003; Redish et al. 1996; Xie et al. 2002; Zhang 1996). In these models, anticipatory firing arises from offset connections between a double ring attractor network. For example, for $\mathrm{CW}$ turns, a HD cell in one layer that is tuned to $50^{\circ}$ is connected to a $45^{\circ}$ tuned HD cell in the second layer; for $\mathrm{CCW}$ turns, a different $50^{\circ}$ tuned $\mathrm{HD}$ cell in the first layer would be connected to a $55^{\circ}$ tuned HD cell in the second layer. Thus turns in one direction excite cells in the second layer that are slightly offset from cells in the first layer. The result is directional firing in the two rings that is slightly out of register in time, such that one leads the other, with no specified behavioral significance. Furthermore, because these models do not distinguish between vestibular, sensory feedback, or motor inputs into the networks, the models make no predictions about how these networks might respond differently in passive versus active conditions.

Two other cases have been reported in which the anticipatory time interval in ADN HD cells has increased after exper- 
imental manipulations: after bilateral PoS lesions (Goodridge and Taube 1997) and after unilateral LMN lesions (Blair et al. 1999). In each case, structures projecting to ADN were removed from the circuit, and the ATI increased rather than decreased in the absence of input from these sources. These two findings suggest that a network functioning without experimental interventions limits the degree of anticipation rather than maximizes it and may indicate that our experimental manipulations did succeed in reducing the amount of information available to the system in our hand-held passive conditions. According to this view, our experimental conditions reduced the limiting effects the network imposes on the ATI, and allowed the ATI to tend toward unconstrained values.

For this reason, it is notable that while there was some trend toward increased ATI in the PoS, the effect was significant for only one of the three measures. Therefore while the PoS might reflect some influence of HD cell activity in the ADN, it does not seem to be merely a passive receiver. Instead, at least some influences on the temporal characteristics of PoS HD cell firing may be independent of the ADN. Given that there are reciprocal connections between the PoS and ADN (van Groen and Wyss 1990), the present results along with those from the PoS lesion experiments (Goodridge and Taube 1997), suggest a two-way flow of temporal influence between the PoS and ADN.

\section{Summary}

Although the results reported here leave uncertain the mechanisms responsible for the ATI, they add to our understanding of the ADN HD signal by showing the independence of anticipatory firing from self-initiated movement. Anticipatory firing was present in both mobile and immobile animals in which we created motor/reafference mismatches through passive movement.

\section{A C K N O W LED G M EN TS}

The authors thank J. Marcroft for technical assistance and S. Wiener for helpful comments on the manuscript.

Present addresses: M. B. Zugaro, Center for Molecular and Behavioral Neuroscience, Rutgers University, 197 University Ave., Newark, NJ 07102; E. J. Golob, Dept. of Psychology, Tulane University, 6823 St. Charles Ave., New Orleans, LA 70118; and G. M. Muir, Psychology Department, St. Olaf College, Northfield, MN 55057-1098.

\section{G R A N T S}

This research was supported by grants from the National Science Foundation (INT-9726719), from the National Institute of Mental Health (MH-48924, MH-01286), and in France from the Centre National d'Etudes Spatiales, Cogniseine, Groupement d'Intérêts Scientifiques.

\section{REFERENCES}

Allen GV and Hopkins DA. Mamillary body in the rat: topography and synaptology of projections from the subicular complex, prefrontal cortex, and midbrain tegmentum. J Comp Neurol 286: 311-336, 1989.

Bassett JP and Taube JS. Neural correlates for angular head velocity in the rat dorsal tegmental nucleus. J Neurosci 21: 5740-5751, 2001a.

Bassett JP and Taube JS. Lesions of the dorsal tegmental nucleus of the rat disrupt head direction cell activity in the anterior thalamus. Soc Neurosci Abstr 27: 852.29, $2001 \mathrm{~b}$.
Blair HT, Cho J, and Sharp PE. Role of the lateral mammillary nucleus in the rat head direction circuit: a combined single unit recording and lesion study. Neuron 21: 1387-1397, 1998.

Blair HT and Sharp PE. Anticipatory head direction signals in anterior thalamus: evidence for a thalamocortical circuit that integrates angular head motion to compute head direction. J Neurosci 15: 6260-6270, 1995.

Blair HT and Sharp PE. Visual and vestibular influences on head-direction cells in the anterior thalamus of the rat. Behav Neurosci 110: 643-660, 1996.

Blair HT, Cho J, and Sharp PE. The anterior thalamic head-direction signal is abolished by bilateral but not unilateral lesions of the lateral mammillary nucleus. J Neurosci 19: 6673-6683, 1999.

Chen LL, Lin LH, Green EJ, Barnes CA, and McNaughton BL. Headdirection cells in the rat posterior cortex. I. Anatomical distribution and behavioral modulation. Exp Brain Res 101: 8-23, 1994.

Chun KS and Robinson DA. A model of quick phase generation in the vestibulo-ocular reflex. Biol Cybern 28: 209-221, 1978

Cho J and Sharp PE. Head direction, place, and movement correlates for cells in the rat retrosplenial cortex. Behav Neurosci 115: 3-25, 2001.

Crommelinck M, Roucoux A, and Veraart C. The relation of neck muscles activity to horizontal eye position in the alert cat. II. Head free. In: Physiological and Pathological Aspects of Eye Movements, edited by A. Roucoux and M. Crommeleinck. The Hague: Junk, p. 379-398, 1982.

Cullen KE and Roy JE. Signal processing in the vestibular system during active versus passive head movements. J Neurophsyiol 91: 1919-1933, 2004.

Fukushima K, Kaneko CR, and Fuchs AF. The neuronal substrate of integration in the oculomotor system. Prog Neurobiol 39: 609-639, 1992.

Gavrilov V, Wiener SI, and Berthoz A. Discharge correlates of hippocampal complex spike neurons in behaving rats passively displaced on a mobile robot. Hippocampus 8: 475-490, 1998.

Golob EJ, Wolk DA, and Taube JS. Recordings of postsubicular head direction cells following lesions of the lateral dorsal thalamic nucleus. Brain Res 780: 9-19, 1998.

Goodridge JP and Taube JS. Interaction between postsubiculum and anterior thalamus in the generation of head direction cell activity. J Neurosci 17: 9315-9330, 1997.

Goodridge JP and Touretzky DS. Modeling attractor deformation in the rodent head-direction system. J Neurophysiol 83: 3402-3410, 2000.

Grasso R, Prevost P, Ivanenko YP, and Berthoz A. Eye-head coordination for the steering of locomotion in humans: an anticipatory synergy. Neurosci Lett 253: 115-118, 1998.

Groenewegen HJ, Ahlenius S, Haber SN, Kowall NW, and Nauta WJH. Cytoarchitecture, fiber connections, and some histochemical aspects of the interpeduncular nucleus in the rat. J Comp Neurol 249: 65-102, 1986.

Guandalini P. The efferent connections to the thalamus and brainstem of the physiologically defined eye field in the rat medial frontal cortex. Brain Res Bull 54: 175-186, 2001

Hahnloser RHR. Emergence of neural integration in the head-direction system by visual supervision. Neurosci 120: 877-891, 2003.

Hardy $\mathrm{O}$ and Corvisier J. Firing properties of preposito-collicular neurones related to horizontal eye movements in the alert cat. Exp Brain Res 110: 413-424, 1996.

Hayakawa T and Zyo K. Retrograde double-labeling study of the mammillothalamic and the mammillotegmental projections in the rat. J Comp Neurol 284: 1-11, 1989.

Kaufman GD, Shinder ME, and Perachio AA. Convergent properties of vestibular-related brain stem neurons in the gerbil. J Neurophysiol 83: 1958-1971, 2000.

Knierim JJ, Kudrimoti HS, and McNaughton BL. Place cells, head direction cells, and the learning of landmark stability. J Neurosci 15: 1648-1659, 1995.

Kubie JL. A driveable bundle of microwires for collecting single-unit data from freely-moving rats. Physiol Behav 32: 115-118, 1984.

Lannou J, Cazin L, Precht W, and Le Taillanter M. Responses of prepositus hypoglossi neurons to optokinetic and vestibular stimulations in the rat. Brain Res 301: 39-45, 1984.

McCrea RA and Baker R. Anatomical connections of the nucleus prepositus of the cat. J Comp Neurol 237: 377-407, 1985.

McCrea RA, Gdowski GT, Boyle R, and Belton T. Firing behavior of vestibular neurons during active and passive head movements: vestibulospinal and other non-eye-movement related neurons. J Neurophysiol 82: 416-428, 1999. 
McFarland JL and Fuchs AF. Discharge patterns in nucleus prepositus hypoglossi and adjacent medial vestibular nuclei during horizontal eye movement in behaving macaques. J Neurophysiol 68: 319-332, 1992.

Meier RK and Dieringer $\mathbf{N}$. The role of compensatory eye and head movements in the rat for image stabilization and gaze orientation. Exp Brain Res 96: 54-64, 1993.

Neafsey EJ, Bold EL, Haas G, Hurley-Gius KM, Quirk G, Sievert CF, and Terreberry RR. The organization of the rat motor cortex: a microstimulation mapping study. Brain Res 396: 77-96, 1986.

Paxinos G and Watson C. The Rat Brain in Stereotaxic Coordinates (4th ed.). New York: Academic, 1998.

Redish AD, Elga AN, and Touretzky DS. A coupled attractor model of the rodent head direction system. Network Comput Neural Syst 7: 671-685, 1996.

Roy JE and Cullen KE. Selective processing of vestibular reafference during self-generated head motion. J Neurosci 21: 2131-2142, 2001.

Roy JE and Cullen KE. Dissociating self-generated from passively applied head motion: neural mechanisms in the vestibular nuclei. J Neurosci 24: 2102-2111, 2004.

Sharp PE, Tinkelman A, and Cho J. Angular velocity and head direction signals recorded from the dorsal tegmental nucleus of Gudden in the rat: implications for path integration in the head direction cell circuit. Behav Neurosci 115: 571-588, 2001.

Siegler I, Israël I, and Berthoz A. Shift of the beating field of vestibular nystagmus: an orientation strategy? Neurosci Lett 243: 93-96, 1998.

Skaggs WE, McNaugton BL, Gothard KM, and Markus EJ. An information theoretic approach to deciphering the hippocampal code. In: Advances in Neural Information Processing Systems. Vol. 5, edited by Hanson SJ, Cowan JD, and Giles CL. San Mateo, CA: Morgan Kaufmann, 1993, vol. 5, p. $1030-1037$.

Stackman RW, Clark AS, and Taube JS. Hippocampal spatial representations require vestibular input. Hippocampus 12: 291-303, 2002.

Stackman RW, Golob EJ, Bassett JP, and Taube JS. Passive transport disrupts directional path integration by rat head direction cells. J Neurophysiol 90: 2862-2874, 2003.

Stackman RW and Taube JS. Firing properties of head direction cells in rat anterior thalamic neurons: dependence upon vestibular input. J Neurosci 17 4349-4358, 1997.
Stackman RW and Taube JS. Firing properties of rat lateral mammillary single units: head direction, head pitch, and angular head velocity. $J$ Neurosci 18: 9020-9037, 1998.

Taube JS. Head direction cells recorded in the anterior thalamic nuclei of freely moving rats. J Neurosci 15: 70-86, 1995.

Taube JS. Head direction cells and the neurophysiological basis for a sense of direction. Prog Neurobiol 55: 225-256, 1998.

Taube JS and Muller RU. Comparisons of head direction cell activity in the postsubiculum and anterior thalamus of freely moving rats. Hippocampus 8 : 87-108, 1998.

Taube JS, Muller RU, and Ranck JB Jr. Head-direction cells recorded from the postsubiculum in freely moving rats. I. Description and quantitative analysis. J Neurosci 10: 420-435, 1990a.

Taube JS, Muller RU, and Ranck JB Jr. Head-direction cells recorded from the postsubiculum in freely moving rats. II. Effects of environmental manipulations. J Neurosci 10: 436-447, 1990b.

van Groen T and Wyss JM. The postsubicular cortex in the rat: characterization of the fourth region of the subicular cortex and its connections. Brain Res 529: 165-177, 1990.

Vogt BA and Miller MW. Cortical connections between rat cingulate cortex and visual, motor, and postsubicular cortices. J Comp Neurol 216: 192-210, 1983.

von Holst $\mathbf{E}$ and Mittelstaedt H. Das Reafferenzprinzip. Wechselwirkung zwischen Zentralnervensystem and Peripherie. Naturwissenschaften 37: 464-476, 1950.

Wiener SI. Spatial and behavioral correlates of striatal neurons in rats performing a self-initiated navigation task. J Neurosci 13: 3802-3817, 1993.

Xie X, Hahnloser RHR, and Seung HS. Double-ring network model of the head direction system. Phys Rev E 66: 041902, 2002.

Zhang K. Representation of spatial orientation by the intrinsic dynamics of the head direction cell ensemble. J Neurosci 16: 2112-2126, 1996.

Zugaro MB, Berthoz A, and Wiener SI. Peak firing rates of rat anterodorsal thalamic head direction cells are higher during faster passive rotations. Hippocampus 12: 481-486, 2002.

Zugaro MB, Tabuchi E, Fouquier C, Berthoz A, and Wiener SI. Active locomotion increases peak firing rates of anterodorsal thalamic head direction cells. J Neurophysiol 86: 692-702, 2001. 